\title{
Ressignificando o engajamento acadêmico com práticas letradas de gamificação
}

DOI: http://dx.doi.org/10.21165/el.v50i2.2992

\section{Gabriel Guimarães Alexandre'}

\section{Resumo}

Considerando-se um contexto marcado por intensa participação das pessoas na internet e por crescente interesse de estudo em metodologias inovadoras e ativas para engajamento de ensino em contexto digital - caso da gamificação -, o objetivo deste artigo é mostrar como o engajamento, pela gamificação em contexto de Ensino Superior, pode ser ressignificado no trabalho com duas atividades gamificadas. Com base em pressupostos teórico-metodológicos dos estudos de letramentos (New Literacy Studies) e da análise do discurso francesa, analisamos as produções textuais quanto ao significado composicional e como este é atrelado a diferentes posicionamentos discursivos assumidos pelos participantes. O corpus é composto de 34 produções textuais multimodais resultantes de um curso de extensão intitulado "Linguagem e Gamificação". Os resultados indicam a relevância de observar-se o engajamento acadêmico do ponto de vista de uma dimensão sócio-histórica constitutiva na/da linguagem.

Palavras-chave: práticas letradas de gamificação; internet; texto multimodal; ensino superior.

1 Universidade Estadual Paulista "Júlio de Mesquita Filho" (UNESP), São José do Rio Preto, São Paulo, Brasil; ggaguimaraes@gmail.com; https://orcid.org/0000-0002-1432-1118 


\title{
Resignifying academic engagement through literacy practices of gamification
}

\begin{abstract}
Considering a context marked by the intense participation of people on the internet and the growing interest in studying innovative and active methodologies for teaching engagement in a digital context - the case of gamification - this paper aims to show how engagement, through gamification in Higher Education context, can be re-signified working with two gamified activities. Based on theoretical and methodological assumptions of New Literacy Studies and French discourse analysis, we analyze textual productions by its compositional meaning and how it is linked to different discursive positions assumed by the participants. The corpus is composed of 34 multimodal texts resulting from an Extension Course entitled "Language and Gamification". The results show us the relevance of observing academic engagement from the point of view of a socio-historical dimension that constitutes general language.
\end{abstract}

Keywords: literacy practices of gamification; internet; multimodal text; Higher Education.

\section{Introdução}

A gamificação é conhecida como aplicação de princípios de jogos (digitais ou analógicos) em contextos "não jogo", enfocando-se engajamento de sujeitos em tarefas ou em resolução de problemas. No cenário brasileiro, é possível vislumbrar aumento de pesquisas que se voltam à temática não só no âmbito da educação ou da aprendizagem de línguas, mas também no da literatura e da produção de textos, conforme constatam Leffa e Vetromille-Castro (2019). Os pesquisadores, no prefácio da organização do número temático em questão, publicado pela revista Linguagem \& Ensino, constatam a presença de diferentes olhares teóricos e metodológicos na investigação sobre gamificação dentro dos estudos da linguagem. O processo, no entanto, acontece há tempos. Por acompanharem o desenvolvimento da cultura (HUIZINGA, 2000 [1938]), os jogos e seus elementos sempre foram utilizados com o objetivo de tornar lúdica uma tarefa que, a princípio, não seria muito atrativa ou interessante.

Esses elementos podem ser encontrados e reconhecidos nas mais variadas esferas de atividade humana. Podemos observar, por exemplo, como a gamificação acontece em sala de aula: um professor, ao observar que o aluno cumpriu determinada tarefa, decide lhe oferecer uma nota bônus ao final do bimestre ou, inclusive, em certos níveis escolares, um doce específico a ser dado ao "vencedor". Esse princípio de recompensa também pode ser observado em empresas, quando estabelecem, por exemplo, algumas metas a serem cumpridas - quantidade de vendas por mês feita pelo funcionário - em troca de bonificação salarial após uma série de procedimentos lúdicos (explícitos ou 
não). Podemos reconhecer, ainda, esses princípios num simples acúmulo de pontos de cartões de crédito para que dado cliente possa convertê-los em prêmios variados. As breves situações apresentadas sobre essa transposição de elementos de jogos para outros contextos marcam a importância dos estudos que se voltam a essa prática social letrada.

Os estudos sobre gamificação estão em ascendência, porque inscritos num contexto marcado, por um lado, pela necessária existência de metodologias ditas "inovadoras" e "ativas" para o contexto educacional; por outro, pela intensa participação das pessoas em atividades on-line. De acordo com o relatório publicado em 2020 do We Are Social2, 4.54 bilhões de pessoas são usuários de internet. Na região das Américas (América do Norte, América Central e América do Sul), 81\% do total de 1.04 bilhão de habitantes encontramse em área urbanizada ou em processo de urbanização e $76 \%$ dessa população tem acesso à internet. Podemos ainda notar, de acordo com o Painel TIC COVID-793, que, inscritos também num cenário pandêmico, cuja dimensão do uso de ferramentas de aprendizagem on-line ganhou relevância diante da interrupção de atividades presenciais em instituições de ensino, houve ampliação da realização de cursos on-line para além do contexto escolar ${ }^{4}$.

Para o que nos interessa discutir neste artigo ${ }^{5}$, o aumento do interesse pela gamificação, relacionado ao atual contexto de participação intensa das pessoas na web, sobretudo em tempos de pandemia, coloca em relevância práticas sociais de leitura e escrita na relação com tecnologias digitais de informação e comunicação (TDIC). Essas tecnologias apresentam forte potencial para corroborar progresso humano, na forma de aprimoramento de tecnologias educacionais que busquem impulsionar a aprendizagem dos sujeitos em contextos formais de ensino - caso da gamificação. Essa possibilidade é trazida fortemente por estudos de "novos" letramentos, segundo posicionamento crítico, colaborativo e transformativo (LANKSHEAR; KNOBEL, 2006, 2011). Para atingir essas qualidades esperadas de um sujeito "letrado na contemporaneidade" (KLEIMAN, 2014), pesquisas sobre a gamificação objetivam, na maioria das vezes, engajar sujeitos em

2 Disponível em: https://wearesocial.com/digital-2020. Acesso em: 20 maio 2021.

3 Disponível em: https://cetic.br/media/docs/publicacoes/2/20200817133735/painel_tic_ covid19_1edicao_livro\%20eletr\%C3\%B4nico.pdf. Acesso em: 20 maio 2021.

4 É importante notar que, além dessa ampliação, segundo o último censo feito pelo Inep sobre a Educação Superior, o número de matrículas, em 2018, na modalidade a distância continuava a crescer, atingindo mais de 2 milhões em 2018, o que já representava uma participação de 24,3\% do total de matrículas de graduação. Disponível em: http://download.inep.gov.br/educacao_superior/ censo_superior/documentos/2019/censo_da_educacao_superior_2018-notas_estatisticas.pdf. Acesso em: 14 out. 2020.

50 estudo e os resultados expostos neste artigo são fruto de recém defendida dissertação de mestrado. Para maiores detalhes, confira Alexandre (2020). 
tarefas específicas, com objetivos específicos. Esse engajamento inscreve-se, também, no rol das metodologias ativas, cuja utilização é crescente nas iniciativas institucionais de diferentes países (BERBEL, 2011; DIESEL; BALDEZ; MARTINS, 2017), pois consideram o aluno como centro dos processos de ensino e aprendizagem - contrapondo-o à ideia de um expectador passivo diante do conhecimento - e possibilitam, assim, que este problematize diferentes situações cotidianas das quais faz parte, produzindo conhecimento. O professor, então, é um facilitador e ativador do aprendizado dos alunos em diferentes níveis do saber.

O tema do engajamento acadêmico é pertinente quando se trata de gamificar contextos formais de ensino. De acordo com Vitória et al. (2018), o engajamento acadêmico é um processo que envolve múltiplos aspectos cuja mobilização permite envolvimento afetivo dos estudantes com o meio e com as atividades acadêmicas. 0 tema da afetividade aparece nessas pesquisas, mas não é o único a ser tratado. De acordo com os autores, o engajamento acadêmico envolve, no mínimo, três dimensões fundamentais: a dimensão afetiva, responsável pelo desejo de aprender, a dimensão cognitiva, centrada no trabalho intelectual e, por fim, a dimensão comportamental, referente à percepção do engajamento nos alunos. Não é nosso objetivo nos debruçarmos sobre o intenso debate que existe sobre esses aspectos do engajamento acadêmico, mas contribuir com a reflexão no que se refere à constatação de que o conceito deve ser entendido "[...] como um processo que não depende apenas do estudante. Este envolve os múltiplos atores que atuam no ambiente acadêmico." (ibid., p. 266).

Por conseguinte, o objetivo deste artigo é mostrar como o engajamento, pela gamificação, pode ser ressignificado no trabalho com produções textuais em Ensino Superior, realizadas a partir de atividades gamificadas, algumas das quais já apresentadas em trabalhos anteriores (ALEXANDRE; KOMESU, 2017, 2019; ALEXANDRE, 2020). Em primeiro lugar, exporemos os pressupostos teóricos de que partimos e que fundamentam nossas escolhas metodológicas. Em seguida, apresentamos análise de dois textos multimodais, resultantes de duas atividades gamificadas, centrando-nos somente em seu aspecto verbo-visual. Nas considerações finais, explicamos as razões pelas quais consideramos que as atividades aqui apresentadas nos possibilitam repensar o engajamento e levar em conta uma dimensão sócio-histórica relevante para os estudos sobre linguagem e gamificação.

\section{Por uma noção de práticas letradas de gamificação}

A definição clássica, nos estudos da gamificação, busca conceituar o fenômeno como uso de princípios de jogos em contextos "não-jogo" (DETERDING et al., 2011, 2014). Fuchs et al. (2014) situam o conceito numa perspectiva ampla e restrita: aquela, por um lado, se referiria ao conceito enquanto processo constituinte de jogos e de experiências lúdicas no desenvolvimento da cultura e da sociedade; esta, por outro lado, se referiria ao conceito 
enquanto prática mais delimitada, enfocando, portanto, o potencial de engajamento que jogos (em sua maioria digitais) podem trazer a contextos "pouco atraentes" - contextos estes entendidos como atividades cotidianas, as quais não costumam incorporar nenhum índice de entretenimento. Por essa razão, "A Gamificação viria suprir essa falta de experiência lúdica encontrada em contextos compreendidos como 'sérios"' (ALEXANDRE, 2020 , p. 18). No contexto da educação, esses princípios dizem respeito, de modo geral, de acordo com Schlemmer e Lopes (2016), a mecânicas - pontos, níveis, placares, medalhas - e a dinâmicas - integrações, desafios, missões, feedback imediato - associadas, quase sempre, a outros elementos que seriam constituintes do processo de gamificar ${ }^{6}$.

Neste artigo, assumimos, conforme Schlemmer e Lopes (2016), que gamificar tem mais a ver com a utilização de estratégias, métodos e conceitos para resolver problemas em situações concretas e reais, do que recriar a situação de jogo em situações abstratas e virtuais. Por essa razão, fundamentados em pressupostos teóricos advindos dos estudos de letramentos (New Literacy Studies) e da Análise do discurso francesa, trabalhamos com a noção de práticas letradas de gamificação, definidas como "[...] práticas sociais de leitura e de escrita que utilizam mecânica e dinâmica de jogos (digitais/analógicos) em outros contextos, como recurso metodológico para o engajamento de sujeitos numa reflexão social e histórica sobre aspectos da língua em funcionamento." (ALEXANDRE, 2020, p. 22).

Inscritos, portanto, na reflexão sobre letramento e gamificação, destacamos forte interesse cada vez mais frequente sobre o conceito como recurso metodológico inovador (LEFFA, 2014; QUADROS, 2016; SOUZA; 2016). Sem a pretensão de mapearmos uma literatura sobre essa relação, destacamos, para nossos interesses, trabalho de Campos e Benedito (2018), que discute uso de elementos de gamificação no contexto educacional com o objetivo de ampliar estratégias pedagógicas para o ensino de língua portuguesa. Ao apresentarem atividades de base gamificada, em busca de desenvolver uma competência leitora nos alunos em questão, indicam a importância de estudos para aprofundarem conhecimentos a respeito de estratégias de linguagem que corroborem criação de atividades de língua materna.

Dessa forma, interessados no estudo do processo de textualização de produções textuais desenvolvidas a partir de atividades de base gamificada, nossa contribuição se dá numa investigação que se diferencia de outras já realizadas, por priorizar "[...] uma concepção de texto como prática social e historicamente compartilhada entre sujeitos situados, no caso deste estudo, num contexto institucional responsável pela formação de futuros profissionais" (ALEXANDRE, 2020, p. 28). Privilegiamos, na elaboração das instruções

6 A quantidade de elementos que os jogos teriam com o objetivo de aplicação em outros contextos potencialmente gamificáveis (os chamados "princípios de gamificação") indica que não há um consenso na literatura sobre o estabelecimento dessas categorias. Para uma discussão detalhada, ver Alexandre (2020). 
das atividades de base gamificada, diferentes aspectos constitutivos do processo de textualização - que não se restringe somente ao momento final da produção do texto, enquanto produto acabado, mas em seu caráter processual - em busca de criar condições mais próximas das que são, de fato, vivenciadas pelos sujeitos - condições, neste caso, decorrentes de um "jogo" de expectativas entre instituição acadêmica e projeção de um futuro profissional de (trabalho com) línguas.

Por tratarmos de debate sobre escrita e letramento no âmbito do contexto formal de ensino, apoiamo-nos na noção de letramentos acadêmicos (LEA; STREET, 2014), sobretudo em como os três modelos propostos se sobrepõem na composição verbovisual identificada nas produções textuais realizadas a partir de atividades gamificadas. Assim, pensar o texto multimodal (KRESS; VAN LEEUWEN, 2006 [1996], 2001) é pensálo na integração com outros modos semióticos ${ }^{7}$, que aparecem de forma constitutiva nos textos. Afinal, de nosso ponto de vista, o olhar para o processo requer discussão de diferentes formas de texto realizadas a partir de atividades de base gamificada e requer, também, a consideração de um diálogo com questões sociais e históricas que condicionam a (re)produção de sentidos em linguagem.

\section{Procedimentos metodológicos}

O corpus de nosso trabalho é formado de 34 (trinta e quatro) produções textuais multimodais, feitas em um Curso de Extensão presencial intitulado "Linguagem e Gamificação", realizado na UNESP (Universidade Estadual Paulista), na cidade de São José do Rio Preto, localizada na região noroeste do estado de São Paulo. De modo geral, objetivamos oferecer subsídios teórico-metodológicos e promover a prática de produção de textos com uso de tecnologias digitais de informação e comunicação (TDIC) entre os participantes, no que se refere à apropriação do conceito de gamificação e seus princípios.

A expectativa era a de que alunos de cursos de Licenciatura ou de professores em serviço se interessassem por metodologias inovadoras para o ensino de línguas em diferentes níveis de ensino. O evento de letramento instaurou-se no período de setembro a outubro de 2018, e inscreveram-se, no curso, o total de 12 (doze) participantes, sendo a maioria pós-graduandos em Estudos Linguísticos (05), graduandos (01 do curso de Letras, 01 do curso de Pedagogia e 01 do curso de Comunicação Social) e professores em serviço (04). A dinâmica do curso consistiu em quatro módulos, cada qual apresentando uma parte teórica - marcada pela apresentação de conceitos fundamentais de gamificação na área

7 Modo semiótico pode ser definido como "[...] recurso socialmente formado e culturalmente dado para produção de sentido." (KRESS, 2009, p. 54). Em busca de se dedicar à discussão do que chamam de "modos específicos" (língua [fala e escrita], imagem, som, gesto, etc.), Kress e van Leeuwen (2001) interessam-se pelo fenômeno da multimodalidade, compreendida como o uso de vários modos semióticos no design de um evento ou produto semiótico (para discussão mais detalhada, ver Alexandre, 2020, p. 33). 
da educação e dos letramentos - e outra parte prática de produção de textos. Durante o curso, duas atividades gamificadas, elaboradas com base em trabalhos anteriores (ALEXANDRE, 2017; ALEXANDRE, 2018), foram aplicadas e três produções textuais foram solicitadas - escrita e reescrita da primeira atividade; escrita da segunda atividade ${ }^{8}$.

As atividades gamificadas foram desenvolvidas levando-se em conta "jogo" deexpectativas entre a universidade e a projeção de um futuro profissional de línguas interessado em metodologias inovadoras para ensino de línguas. Assim, consideramos, na elaboração das atividades, expectativas sobre plano de carreira de um profissional, observadas em demandas do egresso de um Curso de Licenciatura em Letras com base em dois Guias de Profissão (Guia UnAN - Agência de Notícias da UNESP - e Guia do Estudante, Editora Abril). Consideramos, também, mecânicas e dinâmicas de gamificação - em termos de "bons" princípios de aprendizagem (GEE, 2003) - levantadas no jogo digital on-line League of Legends ${ }^{9}$. Para o Curso de Extensão, foram selecionadas duas mecânicas (Árvore de habilidades e Dinâmica de Rotas), por nós associadas a duas dinâmicas, concebidas como "bons" princípios de aprendizagem (para maior aprofundamento sobre o processo de elaboração, ver Alexandre, 2020).

\section{Árvore de habilidades: fortalezas e fraquezas sobre leitura e escrita}

Para a produção da primeira atividade, intitulada "Produção de uma Árvore de habilidades", elegemos a mecânica de mesmo nome (Árvore de habilidades). Essa mecânica é definida como "[...] representação visual hierárquica de customizações, cuja aplicação é feita pelo jogador a fim de atribuir bônus a seu personagem (avatar) no jogo." (ALEXANDRE, 2020, p. 43). Essa mecânica tem o objetivo de auxiliar o jogador na otimização da escolha de itens referentes a determinado avatar - uma vez que uma árvore oferece adicionais de "fortificações" - e na customização de avatares. Nela, ainda, há possibilidade de o jogador distribuir pontos que ele julga ser importantes para "fortificar" determinado avatar dentro do jogo (cf. Figura 1).

8 Com relação à segunda atividade, não solicitamos uma reescrita, mas uma dinâmica de comentários revisionais por parte dos participantes, conforme atividade gamificada solicitada. A codificação apresentada neste artigo, portanto, será feita da seguinte maneira: os elementos separados por hífen (-) se referem ao número e à versão da atividade (A1-a; A1-b; A2-a; A2-b) e, em seguida, à identificação do participante que produziu o texto em questão (P-x).

9 Sucesso como jogo digital on-line, o League of Legends (Liga dos Lendários) foi eleito para elegermos dinâmicas e mecânicas dada sua inserção em práticas cotidianas de sujeitos em diferentes faixas etárias. É considerado, ainda, o jogo digital on-line com mais horas de gameplay gastas do mundo (de acordo com o portal Newzoo, disponível em: https://newzoo.com/insights/ rankings/top-20-core-pc-games/. Acesso em: 20 maio 2021.) No Brasil, conta com milhões de adeptos, audiência que pode ser verificada em campeonatos promovidos pelo jogo, e que já foram transmitidos pela emissora SportTV (disponível em: https://globoesporte.globo.com/esports/lol/. Acesso em: 20 maio 2021). 
Figura 1. Árvore de habilidades do League of Legends

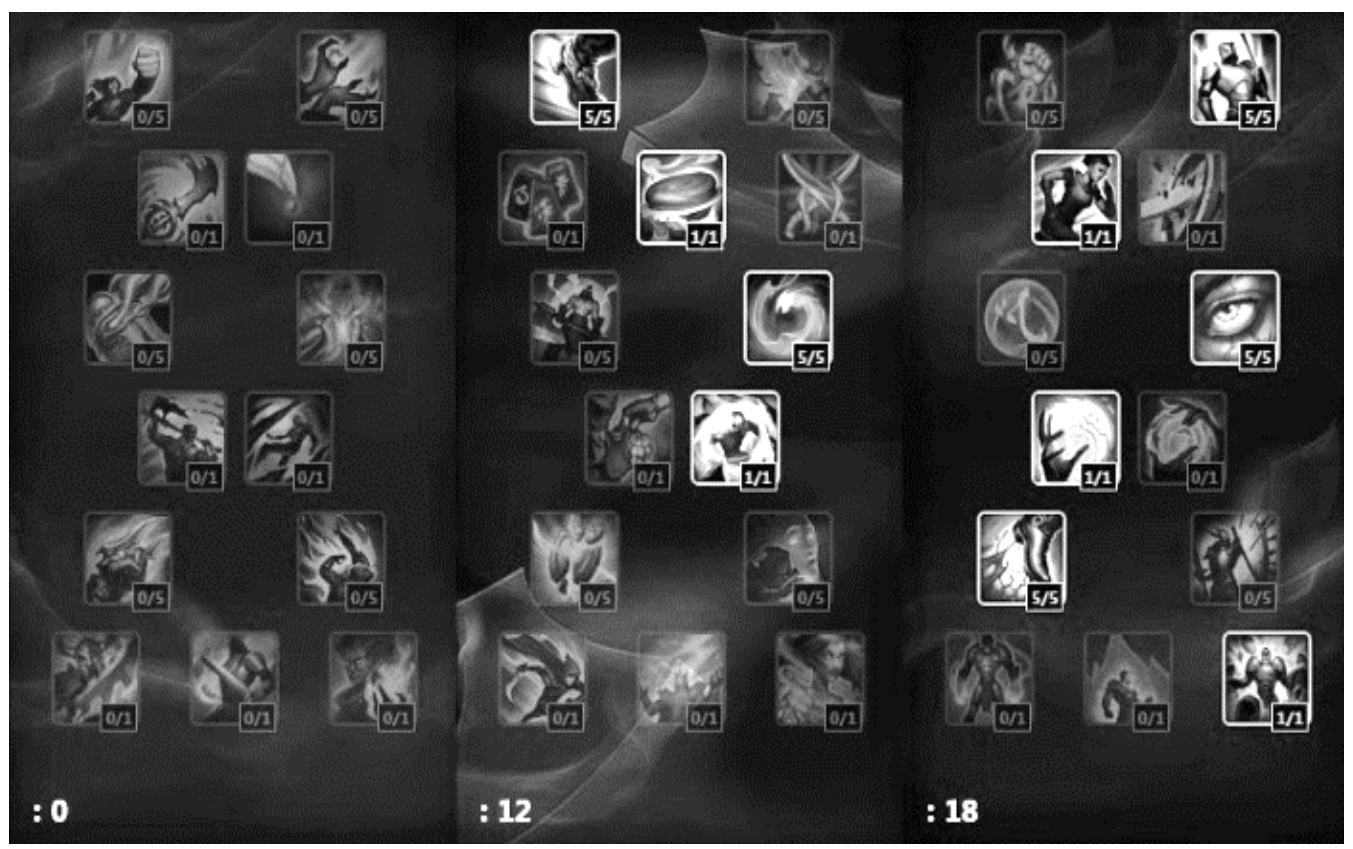

Fonte: Alexandre (2020)

A identificação do princípio da multimodalidade (GEE, 2003) foi por nós associada como dinâmica deste jogo. Isso porque essa dinâmica potencializa a produção de sentidos em linguagem. Exemplo dessa potencialização está, por exemplo, no fato de que, quando o primeiro ícone da segunda coluna da Árvore é habilitado, uma fortificação de aceleramento é dada ao avatar do jogador dentro do jogo - é possível, ainda, dentro de uma partida, ouvir sons de aceleração, como forma de auxiliar o jogador na contextualização de significados que são produzidos. Em nosso trabalho, assumimos que os participantes poderiam criar uma Árvore de habilidades para distribuírem pontos a respeito do que consideram ser "fortalezas" e "fraquezas" de suas habilidades com leitura e escrita. Assumimos, então, "fortalezas" como qualidades e "fraquezas" como fragilidades, associando-as ao levantamento quantitativo dos pontos distribuídos pelos estudantes. Com base nas formulações propostas, a atividade gamificada foi a seguinte:

Crie uma "Árvore de habilidades", considerando as seguintes tarefas: (1) crie sua árvore, tendo em vista suas habilidades referentes à leitura e à escrita; (2) crie desenhos/imagens que se relacionem com os atributos por você levantados. Você tem 30 pontos para distribuir entre as habilidades eleitas. (ALEXANDRE, 2020, p. 48).

Para observar essa distribuição de pontos, consideramos dois critérios. O primeiro diz respeito a quais foram as maiores e as menores pontuações dadas às habilidades, no processo de textualização, bem como a disposição delas na construção de uma 
organização hierárquica, em termos de um significado composicional (valor informacional, saliência e enquadramento). O segundo diz respeito a quais possíveis relações verbais e visuais essas produções tinham, observando uso de dispositivos digitais nesse processo em questão. Do nosso corpus de 34 produções textuais multimodais, 16 são referentes a essa atividade. Apresentaremos, então, uma breve análise de uma Árvore que consideramos ser representativa da reflexão que aqui promovemos.

Figura 2. Árvore de habilidades produzida por participante

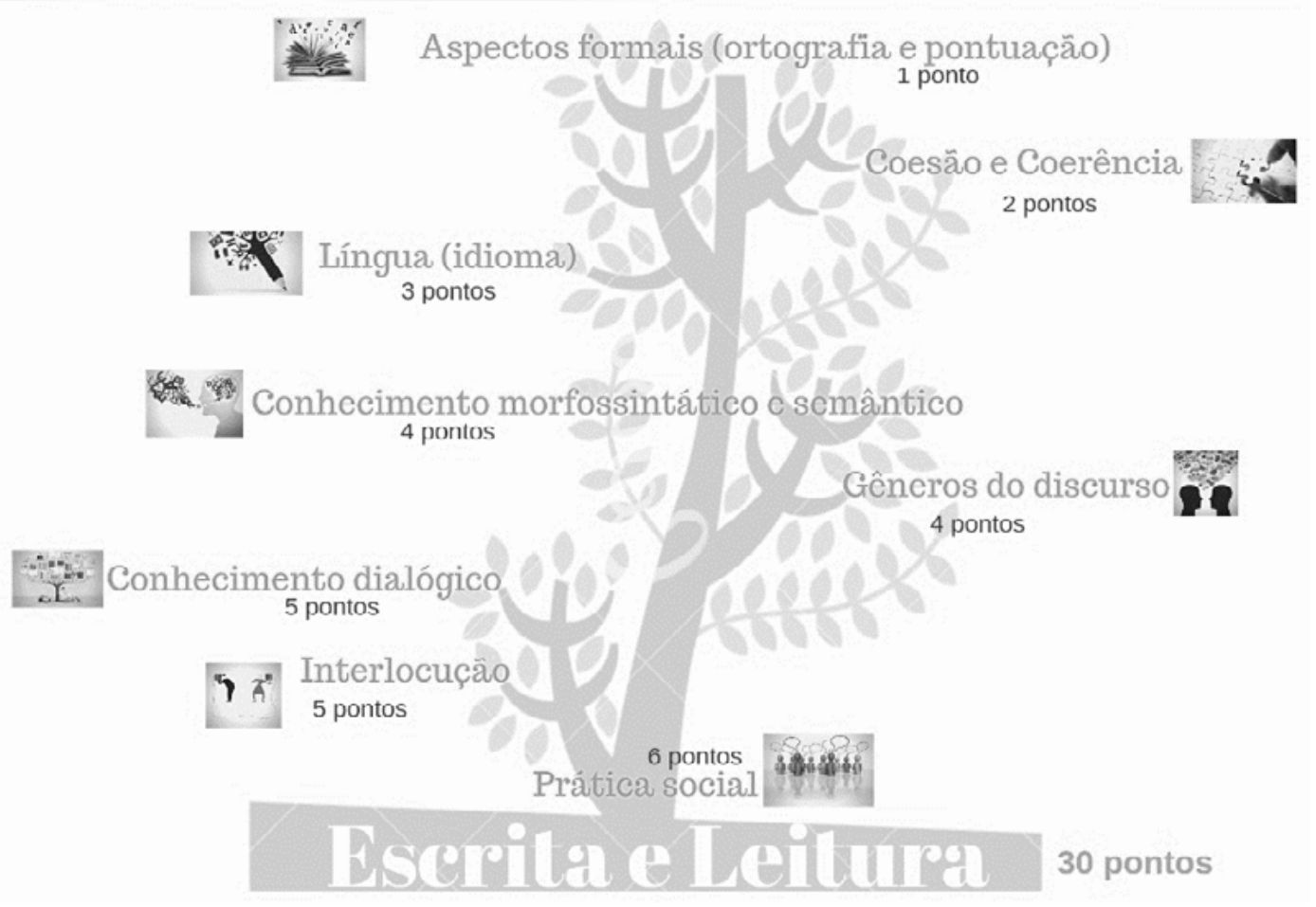

Fonte: produção textual A1-b-P08 (ALEXANDRE, 2020)

A figura acima refere-se a uma produção textual reescrita da primeira atividade (A1b-P08). Essa reescrita feita por este participante é representativa de nossa análise. A escolha, por exemplo, da orientação hierárquica inferior-superior aparece em quase todas as reescritas analisadas. Conforme discutimos, a respeito do funcionamento da Árvore, a permanência dessa disposição gráfica na maioria das produções textuais aponta para um "engajamento dos participantes em relação à expectativa do desenvolvedor do jogo [...]." (ALEXANDRE, 2020, p. 64). Como é possível observar, o elemento mais importante, com base no qual todos os galhos ramificados se estabelecem, é a raiz da Árvore "escrita e leitura" - tomada, então, como fortaleza pelo participante. Foram atribuídos a este elemento o total de 30 pontos, os quais, a partir das linhas de enquadre, passam a ser distribuídos de modo decrescente até a habilidade "Aspectos formais (ortografia e pontuação)", que recebe somente um ponto - logo, habilidade mais frágil do participante. 
Se observamos, ainda, a distribuição de pontos na relação com o que se elege enquanto habilidades de ler e escrever, percebemos que os menores pontos são reservados a aspectos mais "linguísticos" - em sentido estrito - ("Aspectos formais [ortografia e pontuação]", "Coesão e coerência", "Língua e idioma" e "Conhecimento morfossintático e semântico") e os maiores pontos são reservados a aspectos que seriam mais "extralinguísticos" - em sentido amplo - ("Gêneros do discurso", "Conhecimento dialógico", "Interlocução" e "Prática social"). Essa aproximação aponta para uma tendência dessa Árvore (mas também de outras) de se considerar diferentes aspectos que são constitutivos da produção de textos na contemporaneidade. Ao analisarmos, então, a disposição da Árvore na orientação esquerda-direita, o que se percebe é uma leitura inversa daquela privilegiada na leitura da cultura Ocidental, pois as fortalezas estão localizadas mais na parte esquerda, em relação ao restante das habilidades. Podemos dizer que, dada a ramificação da Árvore a partir de uma base comum forte ("escrita e leitura"), a ordem decrescente de aparecimento diz respeito à consideração da raiz como promotora dessas outras qualidades: o que está verbalmente dito poderia estar disposto à direita ou à esquerda, desde que a base comum fortificadora da habilidade fosse mantida.

Na disposição hierárquica e na contabilização da distribuição de pontos, é possível considerar quais habilidades são assumidas como fortes (fortalezas) ou fracas (fraquezas) em relação ao que ele projeta de si (de quais habilidades de ler e de escrever teria). No entanto, esse levantamento não impede o participante de dispor esses elementos da maneira como considera ser relevante ou não, no âmbito do estabelecimento desses elementos na disposição hierárquica da Árvore. Trata-se de uma dinâmica das Árvores de habilidade que "atravessou" a produção textual de certos participantes no processo de textualização verbo-visual. Identificamos, na primeira versão da Árvore em questão, que o participante utilizou ferramentas digitais outras que permitiam melhor integração entre imagem e texto - neste caso, passagem da composição no programa Microsoft Word para o editor de imagens on-line Canva. Constatamos, enfım, que a organização hierárquica, apesar de diferente nas produções textuais analisadas, não ocorre de forma aleatória, mas segundo práticas letradas acadêmicas sócio-historicamente partilhadas numa determinada cultura (ALEXANDRE, 2020, p. 68).

A Árvore de habilidades em questão é representativa das seguintes conclusões de pesquisa: no processo de textualização verbo-visual em práticas letradas de gamificação:

a) há uma associação de "fortalezas" e "fraquezas" - pontos fortes e pontos fracos de si, em práticas letradas acadêmicas - a uma construção hierárquica que corrobora o estabelecimento de significados composicionais e relações verbo-visuais, o que permite observar um posicionamento não individual desses participantes no (seu) processo de produção textual; 
b) a potencialização de criação de sentidos pelo princípio da multimodalidade (GEE, 2003) se faz presente na composição verbo-visual dos textos e, portanto, contribui para o desenvolvimento de competências letradas digitais desejáveis de profissionais que lidam com práticas de leitura e de escrita na contemporaneidade;

c) o posicionamento do profissional que "sabe/faz tudo" coincide com a aproximação entre aspectos mais "linguísticos" (gramaticais/textuais) e aspectos "extralinguísticos", que, no processo de produção textual, são indissociáveis. (ALEXANDRE, 2020, p. 80).

Disso podemos inferir que o engajamento dos participantes, na atividade gamificada, se dá num jogo de posicionamentos discursivos marcado no próprio processo de textualização. Contudo, o engajamento se dá mais com a atividade acadêmica e menos com a (futura) atividade profissional. Isso acontece porque, na condição de aprendentes, aqueles que respondem à instituição são, inevitavelmente, "atravessados" por práticas sociais letradas legitimadas no e pelo contexto acadêmico. Esse atravessamento, conforme Alexandre (2020, p. 81), pode ser reconhecido no fato de que, embora considerem outros aspectos que são constitutivos do processo de textualização em questão,

[...] aspectos linguísticos relacionados à superfície linguística são os mais frequentemente retomados, como se se tratasse de mostrar, ao interlocutor direto (docente do curso de extensão) e ao interlocutor indireto (instituição universitária), conhecimentos de que dispõem, numa associação a um modelo de letramento mais voltado a habilidades de estudo.

\section{Escrita colaborativa de cunho revisional: posições sobrepostas}

A segunda atividade aplicada no Curso de Extensão em questão tem a ver com outra mecânica do League of Legends, conhecida como Dinâmica de Rotas. Essa dinâmica aparece no mapa do jogo Summoner's Rift (Fenda do Invocador). Por ser um jogo MOBA (Multiplayer Online Battle Arena - Jogo Multijogador On-line de Batalha em Arena) há, em sua composição, elementos que permitem customização de personagens, possibilitando que cada jogador possa assumir papéis distintos durante a partida. Quando assumem esses posicionamentos em batalha, os jogadores transitam entre as três possíveis rotas no mapa. A Figura 3 apresenta a tela de seleção de avatares, dentro da qual há uma representação em 3D do mapa de rotas e funções. Dentre as funções, o jogador tem de "causar dano" na batalha ou, ainda, proteger um aliado. As rotas são sempre fixas, enquanto as funções esperadas são a priori flexíveis e intercambiáveis. Essa mecânica faz com que a equipe tenha que imprimir esforços contínuos em prol da vitória e, por isso, é associada ao princípio - enquanto dinâmica - do grupo de afinidade (GEE, 2003). Segundo Gee (2003), este princípio diz respeito ao fato de que um grupo sempre mantém laços 
estreitos ou fortes vínculos por conta de objetivos comuns e de práticas compartilhadas. Dentro desses grupos de afinidade, uma pessoa mais experiente pode descentralizar o conhecimento que detém sobre o jogo em busca de aprimorar a comunidade de que faz parte para alcançar, de forma qualificada, novos objetivos.

Figura 3. Tela de seleção de avatares com mapa de rotas e funções

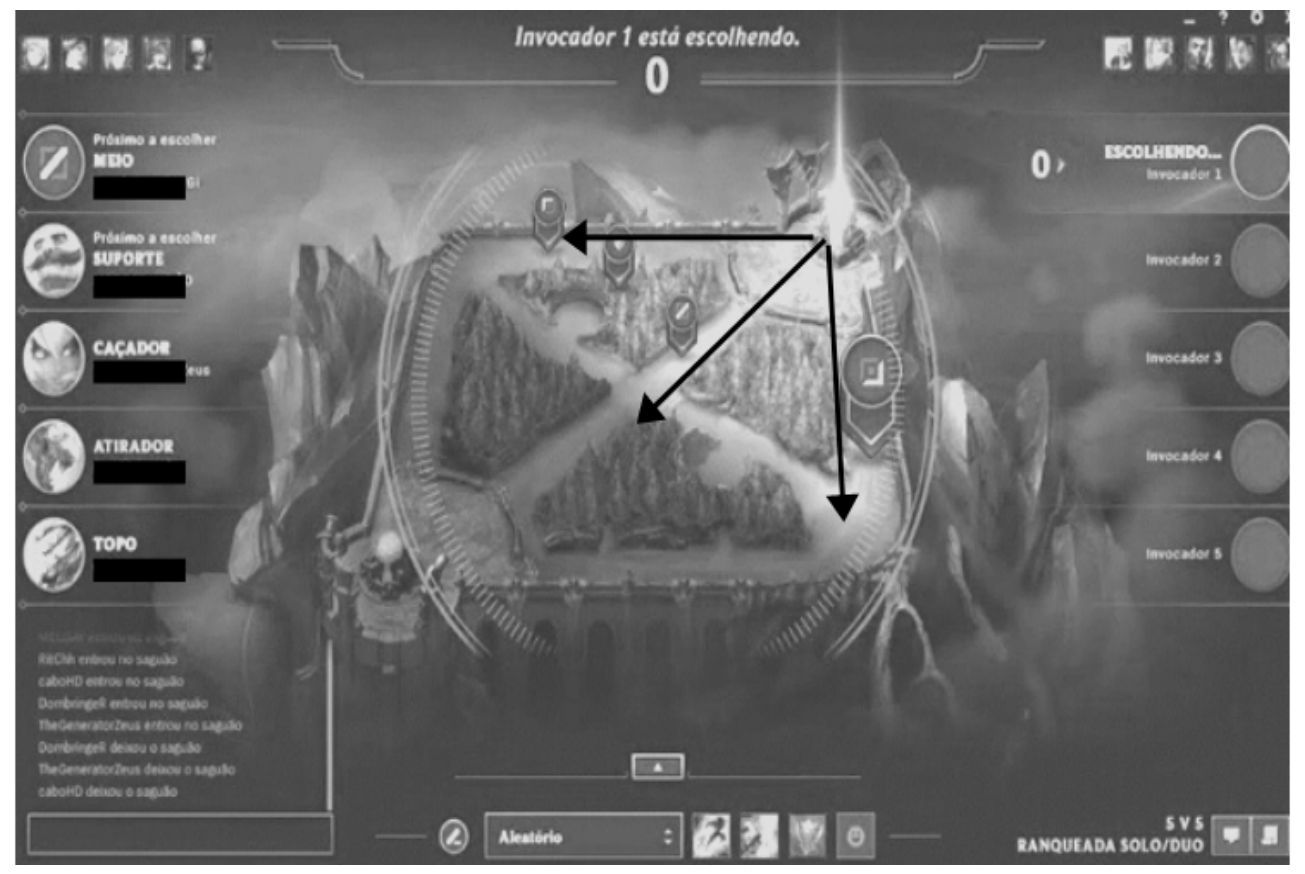

Fonte: Alexandre (2020)

Para elaborar esta segunda atividade gamificada, dividimo-la em dois momentos: pedido de tarefa prévia e apresentação da instrução gamificada. A tarefa prévia consistiu em solicitar aos participantes um resumo crítico, a ser feito individualmente, utilizando a ferramenta Google Documentos, com o limite máximo de 400 palavras, sobre o texto "Letramentos Digitais e Formação de Professores", de autoria do docente pesquisador Marcelo Buzato, da Universidade Estadual de Campinas (UNICAMP). O tema central do texto era a noção de letramento digital na formação de professores. Da instrução prévia, constava o pedido de que o participante levasse em conta um público-alvo de professores da Educação Básica e de que imaginasse que aquele texto fosse feito no blog Passagens ${ }^{10}$. A partir dessa primeira instrução, predefinimos três grupos com três participantes em cada um e uma pasta referente a cada grupo foi criada no Google Drive para que os participantes pudessem acessar as próprias produções e as produções dos

10 O blog pertence ao Prof. Dr. Wanderley Geraldi, professor aposentado da UNICAMP. O site reúne diferentes gêneros, como crônicas, divulgação científica e republicação de artigos científicos do professor. Contudo, atualmente, o endereço do blog (http://blogdogeraldi.com.br/) nem sempre permanece ativo. 
colegas. É importante frisar que a ferramenta Google Documentos foi a escolhida por "[...] possibilitar não apenas produção colaborativa on-line, de acesso gratuito, como também observação e registro do processo de produção textual, com base na edição de textos." (ALEXANDRE, 2020, p. 52).

Solicitamos, num segundo momento, aos participantes, para que, na realização da atividade de comentar o texto do outro, levassem em consideração os critérios preestabelecidos pela atividade prévia, isto é, (1) produção de resumo crítico; (2) limite máximo de 400 palavras; (3) consideração de professores de Educação Básica como público-alvo; (4) consideração de que o texto seria postado no blog Passagens. No que se refere à apresentação da instrução gamificada, propusemos relacionar as mecânicas de rota e função a funções do âmbito do letramento acadêmico, sob a forma de "funções de universitários na produção textual" ${ }^{11}$. Segue a instrução:

Com base na produção do resumo crítico, forme grupos de, pelo menos, três (03) pessoas cada um. Observe atentamente o quadro de funções. Depois, siga as seguintes tarefas: (1) acesse, no Módulo 3 do Google Drive, a pasta referente a seu grupo; (2) comente os resumos dos demais integrantes de seu grupo, assumindo, para si, cada uma das diferentes funções estabelecidas; (3) identifique os comentários a serem feitos, a partir de cada função, com a letra inicial: E de Editor, $\mathbf{R}$ de Revisor e $\mathbf{C}$ de Crítico; (4) não aceite as sugestões deixadas por outros integrantes. (ALEXANDRE, 2020, p. 52).

Com base nos recortes metodológicos necessários à organização do material (conforme explicamos, com detalhes, em Alexandre, 2020), dessa segunda atividade, recolhemos o total de 18 (dezoito) produções textuais, considerando-se que 12 (doze) produções foram resultantes de comentários feitos a cada membro de um grupo no qual um participante se inseriu, e seis (06) produções textuais são resultantes da atividade prévia feita por cada um. Com esta atividade, nosso objetivo era observar como os participantes, no processo de textualização, desempenhariam tarefas predeterminadas segundo instrução gamificada, observando-se ferramentas digitais de uso frequente e trabalho individual/ coletivo no processo de escrita colaborativa on-line de cunho revisional (PINHEIRO, 2011). Comentaremos, a seguir, uma produção textual resultante de comentários feitos de um grupo em um texto de um participante (P2-b-P08) cuja discussão pode ser representativa dos dados obtidos (cf. Figura 4). Esses resultados apontam para a sobreposição esperada de diferentes funções assumidas - tal como na dinâmica proposta pelo jogo - as quais colocam em evidência identidades sociais construídas na relação entre texto

11 Foram propostas três funções: Editor - tem habilidade com diagramação, padronização, correção gramatical e de texto. Revisor - tem habilidade com revisão de texto, com especial atenção à correção gramatical e de texto. Crítico - Tem habilidade em auxiliar todas as outras, com especial atenção a aspectos interlocutivos do gênero solicitado. (Adaptado de Alexandre, 2020). 
efetivamente produzido e comentários, no texto alheio, como forma de engajamento promovido pela atividade gamificada.

Figura 4. Sobreposição entre as funções de Crítico e de Editor

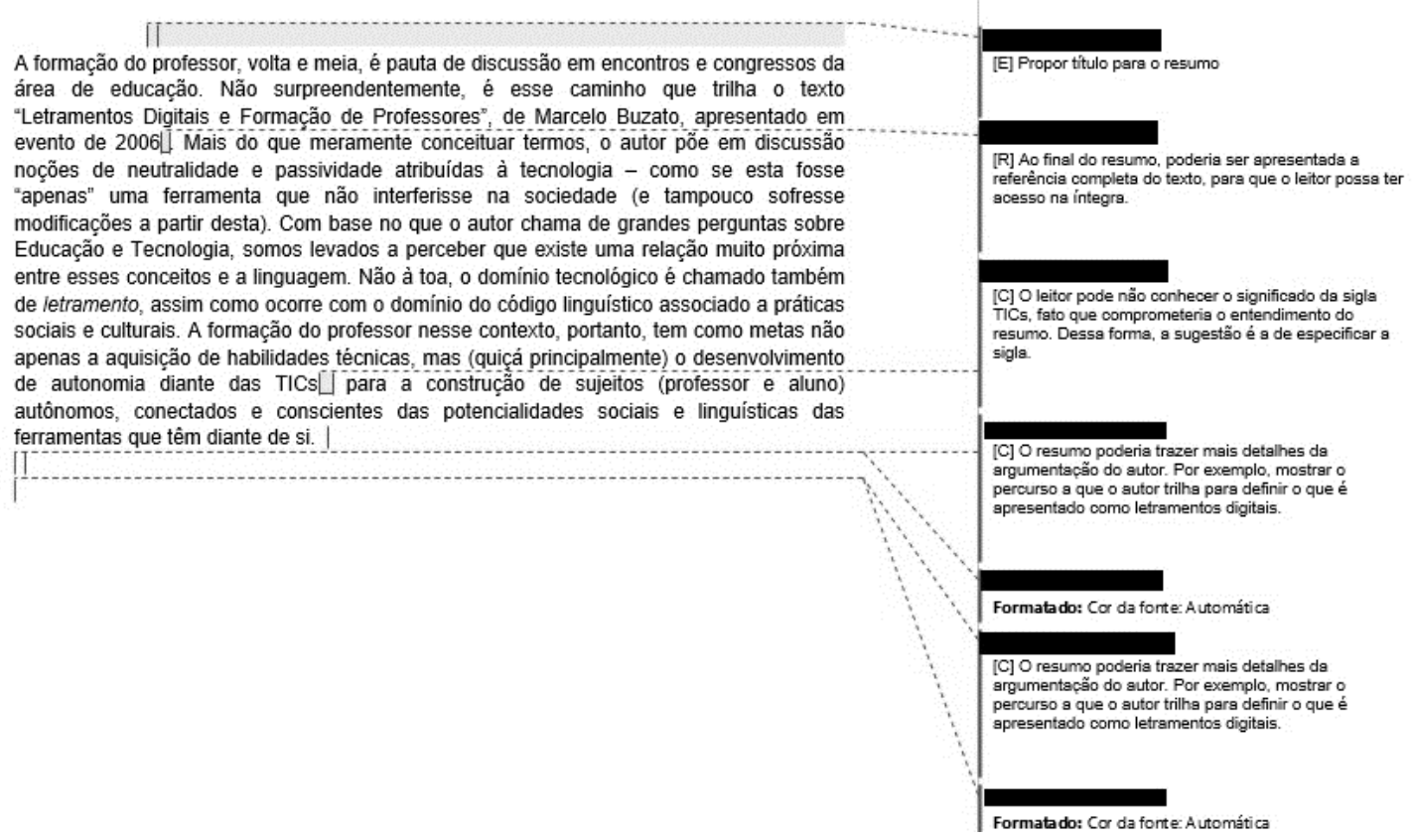

Fonte: Produção textual P2-b-P08 (ALEXANDRE, 2020)

Apresentamos, aqui, uma possibilidade de sobreposição (há outras) que acontece, por exemplo, entre as funções de Crítico e de Editor. O Editor propõe apenas uma ação ao autor do texto do resumo crítico: "[E] propor título para resumo". Com base no que havia sido apresentado aos participantes do Curso, o título é importante aspecto de interlocução. Contudo, a presença desse aspecto, no resumo, é um fator a ser observado na função de Crítico, na avaliação dos efeitos de sentido do título, do impacto produzido no leitor. O restante das inserções de comentários foi atribuído apenas à função de Revisor "[R] Ao final do resumo, poderia ser apresentada a referência completa do texto, para que o leitor possa ter acesso na íntegra". Além disso, a questão da formatação não foi comentada por nenhuma das funções. Conforme argumentamos em Alexandre (2020), a própria ferramenta apresenta determinados padrões de maneira automatizada, razão que justificaria a ausência desse tipo de comentário no texto. Então, os comentários "[C] O leitor pode não conhecer o significado da sigla TICs, fato que comprometeria o entendimento do resumo. Dessa forma, a sugestão é a de especificar a sigla." e "[C] O resumo poderia trazer mais detalhes da argumentação do autor. Por exemplo, mostrar o percurso que o autor trilha para definir o que é apresentado como letramentos digitais" são esperados de uma função que se ocupa do processo interlocutivo (explícito ou implícito) do resumo crítico. A ausência de composição visual não anula esse texto enquanto multimodal: a diagramação do texto garante essa integração de modos, uma vez que reproduz aquela 
já legitimada pela instituição acadêmica - a normatização da Associação Brasileira de Normas Técnicas (ABNT). O modo como os participantes se posicionam por meio dessa dinâmica parece apontar para

[...] um modelo de habilidades de estudo (com excessivas ênfases à superfície linguística) ou de socialização acadêmica (com necessidade de se voltar a modelos estabelecidos do que seria um "resumo" no meio acadêmico) (LEA; STREET, 2014), advindos de uma imagem da universidade em que o conceito de texto (de linguagem) ainda estaria restrito a esses aspectos. (ALEXANDRE, 2020, p. 96).

O que se pode perceber, também, é a relação de autoridade que "atravessa" os participantes nesse processo de textualização em específıco. A busca por corresponder a identidades sociais - sócio-historicamente estabelecidas - faz parte de um esforço coletivo de os participantes aderirem ao modus operandi da produção textual no Ensino Superior. Essa adequação pode igualmente ser explicada pela ausência da utilização de imagens - a ausência estava "presente" em todos os textos dessa segunda atividade. Conforme argumentamos em Alexandre (2020), ao mesmo tempo em que se identifica uma atenção dispensada à necessidade de trabalhar-se com a integração entre diferentes semioses no trabalho com o texto, identifica-se, também que pouco se trabalha com multimodalidade em práticas letradas acadêmicas. Esse "jogo" de expectativas entre instituição, participante e sociedade mostra relação de autoridade, poder e identidade; uma sobreposição, portanto, do modelo de letramentos acadêmicos nessas práticas de letramento gamificadas. Por isso, chegamos à conclusão de que

[...] a possibilidade de redigir um texto de resumo crítico com base em instrução gamificada possibilita, contraditoriamente, uma não adesão dos sujeitos escreventes à relação interlocutiva, à circulação desses textos em blogs. A ausência de imagens, por exemplo, e o não comentário de nenhum dos participantes sobre essa ausência, é índice que demonstra essa tensão e a coerção dos discursos. (ALEXANDRE, 2020, p. 97).

\section{Considerações finais}

Objetivamos, neste artigo, por meio da exposição dos principais resultados de pesquisa já concluída, como o engajamento, pela gamificação em contexto de Ensino Superior, pode ser ressignificado no trabalho com duas atividades gamificadas. Com relação à primeira atividade aplicada, apresentamos um dado representativo que apontou para a não aleatoriedade de distribuição de pontos sobre habilidades de leitura e escrita que os participantes têm na associação de "fortalezas" e "fraquezas" de si - pontos fortes e pontos fracos, qualidades e dificuldades a si atribuídos no processo de textualização. O engajamento com essa atividade se materializou sob a forma de uma projeção de profissional de línguas que tem de lidar com a integração de diferentes modos semióticos 
no processo de comunicação da contemporaneidade. Ele se dá, no entanto, mais com a atividade acadêmica e menos com a atividade profissional, "[...] uma vez que, na condição de universitários, aqueles que respondem à instituição são mais fortemente "atravessados" por práticas letradas acadêmicas." (ALEXANDRE, 2020, p. 100).

Com relação à segunda atividade aplicada, o modo como os participantes se posicionam por meio da dinâmica de funções (de Editor, de Revisor e de Crítico) parece apontar, nos termos de Lea e Street (2014), para um modelo de habilidades de estudo - no que diz respeito à ênfase na superfície linguística - ou de socialização acadêmica - na consideração de modelos preestabelecidos. De nosso ponto de vista, uma imagem da universidade que privilegia práticas letradas acadêmicas ditas mais "tradicionais" - com produção de textos verbais e de gêneros discursivos como resumo, resenha, fichamento - ainda é preponderante entre os sujeitos (docentes e discentes). Assim como afirmamos em Alexandre (2020), em uma sociedade em que o uso de tecnologias digitais de informação e comunicação é amplamente cobrado (também do [futuro] professor), a ausência dessas práticas sociais letradas na instituição é reproduzida em produções textuais escritas pouco afeitas a uma linguagem de posts de blog, segundo determinada diagramação, segundo uso de hiperlinks ou de textos verbo-visuais, em determinado modo de circulação que tem o potencial de atingir número maior de leitores.

Essa dinâmica que acontece na segunda atividade não deixa de mostrar-nos o modelo de letramentos acadêmicos (LEA; STREET, 2014) também presente, pois as relações de poder e de autoridade endossadas pela universidade fazem com que o sujeito escrevente sofra constrições no processo de produção textual. Em paralelo com a primeira atividade, observamos, enfim, que a adesão dos sujeitos escreventes se dá numa atividade - Árvore de habilidades - incomum no contexto escolar/universitário, levando-se em conta que foi criada para esta pesquisa com base nos princípios de gamificação. Diferentemente do que acontece na segunda atividade, a qual, de certa forma, é mais conhecida pelos participantes inseridos no contexto acadêmico - produção de resumo.

Assim, a noção de práticas letradas de gamificação orienta este trabalho na investigação de uma dinâmica de engajamento/comprometimento do participante com uma identidade profissional cujo entendimento não precisa passar, necessariamente, por entretenimento ou ludicidade, traços comumente atribuídos a jogos/games, mas por uma consideração (reconhecimento) da relevância de modos de interação com o(s) outro(s) na/da linguagem. Afınal, se a gamificação é a consciência, pelos estudos científicos, de que nossa cultura é organizada segundo princípios gerais de jogos, explicitá-la ou com ela trabalhar é, ao mesmo tempo, levar em conta aspectos sócio-historicamente relevantes e constitutivos da produção dos textos, dos sujeitos e da linguagem. 


\section{Agradecimentos}

O presente trabalho só foi possível de ser realizado graças ao financiamento da Coordenação de Aperfeiçoamento de Pessoal de Nível Superior - Brasil (CAPES) - Código de Financiamento 001, e ao apoio do Grupo de Pesquisa Práticas de escrita e leitura em contexto digital (CNPq), liderado pela Profa. Dra. Fabiana Komesu (UNESP).

\section{REFERÊNCIAS}

ALEXANDRE, G. G. Práticas letradas de gamificação: estudo do processo de textualização no Ensino Superior. 2020. Dissertação de Mestrado (Estudos Linguísticos) - Instituto de Biociências, Letras e Ciências Exatas, Universidade Estadual Paulista "Júlio de Mesquita Filho", São José do Rio Preto, 2020.

ALEXANDRE, G. G. Práticas letradas acadêmicas e uso de tecnologias digitais: gamificação no processo de produção textual na universidade. 2018. Relatório de iniciação científica (Licenciatura em Letras) - Instituto de Biociências, Letras e Ciências Exatas, Universidade Estadual Paulista "Júlio de Mesquita Filho", São José do Rio Preto, 2018.

ALEXANDRE, G. G. Práticas letradas acadêmicas e uso de tecnologias digitais: gamificação no processo de produção textual na universidade. 2017. Relatório de iniciação científica (Licenciatura em Letras) - Instituto de Biociências, Letras e Ciências Exatas, Universidade Estadual Paulista "Júlio de Mesquita Filho", São José do Rio Preto, 2017.

ALEXANDRE, G. G.; KOMESU, F. Academic Literacies and gamification: "strengths" and "weaknesses" in the visual-verbal textualization process. Linguagem \& Ensino: Gamificação, Pelotas, v. 22, n. 4, p. 1199-1220, out./dez. 2019. Disponível em: https:// periodicos.ufpel.edu.br/ojs2/index.php/rle/article/view/16456. Acesso em: 28 set. 2020.

BERBEL, N. A. N. As metodologias ativas e a promoção da autonomia de estudantes. Semina: Ciências Sociais e Humanas, Londrina, v. 32, n. 1, p. 25-40, 2011.

BUZATO, M. E. K. Letramentos Digitais e Formação de Professores. III Congresso IberoAmericano EducaRede: Educação, Internet e Oportunidades. São Paulo, Brasil, 2006.

CAMPOS, K. do S. da R.; BENEDITO, D. C. Gamificação no processo de ensino e aprendizagem de leitura em Língua Portuguesa. Revista Intercâmbio, São Paulo, v. 38, p. 26-45, 2018. Disponível em: https://revistas. pucsp.br/intercambio/article/ view/39233/27428. Acesso em: 04 out. 2020. 
DETERDING, S. Eudaimonic design, or: six invitations to rethink gamification. In: FUCHS, M. et al. Rethinking Gamification. Milton Keynes, UK: Meson Press, 2014.

p. 305-331. Disponível em: http://gamification-research.org/2014/06/edited-volume rethinkinggamification-out. Acesso em: 05 out. 2020.

DETERDING, S. et al. Gamification: Toward a Definition. CHI 2017 Workshop Gamification: Using Game Design Elements in Non-Game Contexts. Vancouver, p. 1-4, 2011.

Disponível em: http://gamification-research.org/wp-content/uploads/2011/04/02-

Deterding-Khaled-Nacke-Dixon.pdf. Acesso em: 04 out. 2020.

DIESEL, A.; BALDEZ, A. L. S.; MARTINS, S. N. Os princípios das metodologias ativas de ensino: uma abordagem teórica. Revista Thema, v. 14, p. 268-288, 2017.

FUCHS, M. et al. Rethinking Gamification. Milton Keynes, UK: Meson Press, 2014. Disponível em: http://gamification-research.org/2014/06/edited-volume rethinkinggamification-out. Acesso em: 05 out. 2020.

GEE, J. P. What video games have to teach us about learning and literacy. New York: Palgrave MacMillan, 2003.

HUIZINGA, J. Homo Ludens: o jogo como elemento da cultura. Tradução João Paulo Monteiro. 4. ed. São Paulo: Perspectiva, 2000 [1938].

KLEIMAN, A. B. Letramento na contemporaneidade. Bakhtiniana: Revista de Estudos do Discurso, v. 9, p. 79-97, 2014.

KRESS, G.; LEEUWEN, T. van. Reading Images: the grammar of visual design. London: Routledge, 2006 [1996].

KRESS, G.; LEEUWEN, T. van. Multimodal discourse: the modes and media of contemporary communication. England: Hodder Arnold Publication, 2001.

LANKSHEAR, C.; KNOBEL, M. New literacies. 3. ed. England: Open University Press, 2011.

LANKSHEAR, C.; KNOBEL, M. New Literacies: Everyday practices and classroom learning. 2. ed. Glasglow: McGraw-Hill/Open University Press, 2006. 
LEA, M.; STREET, B. O modelo de "letramentos acadêmicos": teoria e aplicações.

Tradução F. Komesu e A. Fischer. Filologia e Linguística portuguesa, v. 16, n. 2, p. 477-493, 2014. Disponível em: https://www.revistas.usp.br/flp/article/view/79407. Acesso em: 05 out. 2020.

LEFFA, V. J. Gamificação adaptativa para o ensino de línguas. Congresso IberoAmericano de Ciência, Tecnologia, Inovação e Educação. Buenos Aires. Anais, p. 1-12, 2014. Disponível em: http://www.leffa.pro.br/textos/trabalhos/Gamificacao_Adaptativa_Leffa. pdf. Acesso em: 05 out. 2020.

LEFFA, V. J.; VETROMILLE-CASTRO, R. Gamificação. Linguagem \& Ensino: Gamificação, Pelotas, v. 22, n. 4, p. 975-981, out./dez. 2019. Disponível em: https://periodicos.ufpel. edu.br/ojs2/index.php/rle/article/view/17766/10803. Acesso em: 28 dez. 2020.

QUADROS, G. B. F. de. A gamificação no ensino de línguas online. 2016. Tese (Doutorado em Letras) - Universidade Católica de Pelotas, Rio Grande do Sul, 2016. Disponível em: http://www.leffa.pro.br/tela4/Textos/Textos/teses_online/Gerson_Bruno_Forgiarini_de_ Quadros.pdf. Acesso em: 05 out. 2020.

SOUZA, R. S. dos S. Gamificação: contribuições para a produção de textos narrativos. 2016. Dissertação (Mestrado Profissional em Letras) - Universidade Estadual de Montes Carlos, São Paulo, 2016.

SCHLEMMER, E.; LOPES, D. de Q. Avaliação da aprendizagem em processos gamificados: desafios para apropriação do método cartográfico. In: ALVES, L.; COUTINHO, I. de (org.). Jogos digitais e aprendizagem: fundamentos para uma prática baseada em evidências. Campinas: Papirus, 2016. p. 179-208. 